DOI 10.22455/2619-0311-2018-3-161-184

УДК $821.161 .1+8.82 .0$

ББК $83.3(2 \mathrm{POC}=\mathrm{PYC}) 1$

Д.П. Ивинский

Роман Достоевского «Идиот» и альманах Карамзина «Аглая»

\title{
D.P. Ivinskij \\ Dostoevsky's novel "Idiot" and the almanac of Karamzin \\ "Aglaya"
}

Об авторе: Дмитрий Павлович Ивинский, доктор филологических наук, профессор филологического факультета МГУ имени М.В. Ломоносова, Москва.

E-mail:dmitrij_ivinskij@mail.ru

Аннотация: В статье показано, что в альманахе Карамзина «Аглая» был оформлен первый вариант того литературно-идеологического пространства, с которым взаимодействовал Достоевский-автор романа «Идиот». Карамзин обобщил ту совокупность дилемм, которые связывают противопоставление зла и истины с темой спасения, преимущественно в аспекте ее соотнесенности с широко понимаемой сферой надысторического. Данная проблематика у Карамзина и у Достоевского сочеталась с «руссоизмом», с выбором между представлением о развитии как прогрессе и как регрессе, с проблемой «естественного человеке» как идеале, чье воплощение в реальности общественной жизни невозможно, а присутствие необходимо, и в обоих случаях устремлено за пределы земного времени-пространства. Познание сокровенного зла связывалось с мотивами душевной «невинности» и «болезни» / «болезненности», физической и душевной, путешествия как нравственного опыта; в сердцевине же «падшего мира» оказывалась «опрокинутая» в кругозор Лебедева матричная формула о «милом прахе» и «радостном утре». В той мере, в какой каждое отдельное произведение Достоевского взаимодействовало с данной парадигмой, его «карамзинизм» открывается разными смысловыми гранями (при том, что каждая из этих граней определенным образом соотносится и с другими сегментами «литературного пространства», в т.ч. с «готическим романтизмом», обычно не без оснований возводимым к повести «Остров Борнгольм», впервые напечатанной в «Аглае»). В пределе развертывания темы духовной катастрофы возникает и тема конца истории, столь занимавшая Достоевского и впервые намеченная у Карамзина, размышлявшего об обозначившейся во 
французской революции тенденции к исчерпанию нравственных возможностей истории, оформившего эти размышления в «Аглае» в форме эпистолярной дискуссии с открытым финалом, подчеркнувшим драматизм темы, и тем самым открыл путь другим русским писателям, соприкасавшимся с вызовами «последних вопросов», в т.ч. Достоевскому.

Ключевые слова: Карамзин, Достоевский, Руссо, Бонне, альманах, роман, Аглая

Для цитирования: Ивинский Д.П. Роман Достоевского «Идиот» и альманах Карамзина «Аглая» // Достоевский и мировая культура. 2018. № 3. С. 161-184. DOI: 10.22455/2619-0311-2018-3-161-184

Information about the author: Dmitrij P. Ivinsky, Doctor of Philology, Professor of the Philological Faculty of Lomonosov Moscow State University, Moscow.

E-mail:dmitrij_ivinskij@mail.ru

Abstract: The article shows that Karamzin's "Aglaya" was the first version of the literary and ideological paradigm that was crucial for Dostoevsky's novel "Idiot". Karamzin summarized the group of ideas that created the connection between the opposition of evil and truth and the theme of salvation. Karamzin and Dostoevsky combined these problems with "Russoism", with the concept of development as progress and regression, and the problem of "natural man" as an ideal; they assumed that it's realization was impossible, however they believed that it's presence was necessary, and in both cases these concepts were directed beyond the limits of space and time. The knowledge of secret evil was associated with the motives of spiritual "innocence" and "sickness" / "painfulness", physical and mental, travel as a moral experience; at the core of the "fallen world" were Lebedev's formulas of "sweet dust" and "joyful morning". However Dostoevsky's works were connected not only with "Karamzinism" but with "Gothic Romanticism" as well (it's necessary to underline that this tradition can be bind together with Karamzin's "Island of Borngolm", first published in "Aglaya").

The theme of spiritual catastrophe was linked with the theme of the end of history, which occupied Dostoevsky so much and was first outlined by Karamzin. Karamzin wrote about the exhaustion of the moral potential of history during the French Revolution, he shaped these reflections in "Aglaya" in the form of an epistolary discussion with an open final, emphasizing the drama of the topic, and thus opened the way for other Russian writers who came into contact with the challenges of the "last questions”, including Dostoevsky.

Keywords: Karamzin, Dostoevsky, Rousseau, Bonn, almanac, novel, Aglaya 
Хрестоматийно известная эпитафия Карамзина «Покойся милый прах до радостного утра» (1792) следующим образом включена в текст романа «Идиот»: «Генерал даже покраснел, говоря.

- Да Лебедев и не мог быть в двенадцатом году в Москве <...>.

- Во-первых, это; но, положим, он тогда уже мог родиться; но как же уверять в глаза, что французский шассёр навел на него пушку и отстрелил ему ногу, так, для забавы; что он ногу эту поднял и отнес домой, потом похоронил ее на Ваганьковском кладбище и говорит, что поставил над нею памятник с надписью с одной стороны: «Здесь погребена нога коллежского секретаря Лебедева», а с другой: «Покойся, милый прах, до радостного утра», и что, наконец, служит ежегодно по ней панихиду (что уже святотатство) и для этого ежегодно ездит в Москву. В доказательство же зовет в Москву, чтобы показать и могилу, и даже ту самую французскую пушку в Кремле, попавшую в плен; уверяет, что одиннадцатая от ворот, французский фальконет прежнего устройства.

- И притом же ведь у него обе ноги целы, на виду! - засмеялся князь. - Уверяю вас, что это невинная шутка; не сердитесь» [Достоевский 1972-1990: VIII, 411].

Вероятно, Достоевский учитывает здесь не только эпитафию Карамзина, но и его перевод знаменитой идиллии Соломона Гесснера «Деревянная нога». При этом Лебедев оказывается «карамзинистом» и в ином контексте, который задают ключевые понятия «словаря сентиментализма»:

«- Да тут и понимать совсем нечего! - даже привскочил на стуле Лебедев: - одна, одна чувствительность и нежность - вот все лекарство для нашего больного. Вы, князь, позволяете мне считать его за больного?» [Достоевский 1972-1990: VIII, 375; курсив мой].

Что нам дают эти цитаты? Только возможность сделать вывод о том, что карамзинская тема заявлена Достоевским как пригодная для пародийных упражнений. Но, во-первых, ни эпитафия 1792 г., ни перевод идиллии не приближают нас к заявленной теме, а во-вторых, остается неясным, зачем понадобились Достоевскому эти пародийные упражнения ${ }^{1}$, и сводится ли к ним его интерес к Карамзину, а если нет, то нужно выяснить, насколько принципиален этот «карамзинизм» Достоевского для понимания его романа (или романов).

1 Как известно, текст данной эпитафии был избран братьями Достоевскими для памятника на могиле их матери [Летопись: 1,36$]$; из этого следует, что отношение их к Карамзину отнюдь не было чисто «игровым» и что словесные упражнения Лебедева характеризуют именно его, а не автора романа «Идиот». 
Допустим, что удастся выявить в тексте Достоевского скрытые отсылки к Карамзину르, подобные только что приведенной. Остановимся на ней чуть подробнее. В цитате из Достоевского мы выделили курсивом слова «чувствительность» и «нежность». Они входят в словарь Карамзина? Безусловно. Но ведь не только в его словарь: вряд ли нужно доказывать, что ими пользовались все «чувствительные авторы», в том числе многочисленные эпигоны Карамзина, компрометировавшие свой образец - отчего бы не допустить, что именно этот факт учитывает Достоевский? Далее, если все же он имел в виду именно Карамзина, то какие именно его произведения? Здесь останавливаемся, хотя число подобных простых вопросов, на которые трудно ответить, без труда можно было бы увеличить.

Приведем другой пример, еще более выразительный. Давно замечено несоответствие имени и фамилии Льва Николаевича Мышкина, главного героя романа «Идиот»: фамилия соответствует доминантам его поведения, умонастроения, «психотипа», имя - нет (при этом, как известно, антитеза льва и мыши принадлежит к числу наиболее древних в европейской аллегорической литературе благодаря басенной традиции, восходящей к Эзопу, басню которого «Лев и мышь» переводили Жан де Лафонтен, а в России - учитывавшие его перевод А.П. Сумароков и И.А. Крылов). Несовпадение имени и темперамента героя Достоевского находит соответствие у Карамзина в «Рыцаре нашего времени» (1803), повести, из которой, как часто полагают комментаторы, выросла русская проза XIX в. Напомним небольшой фрагмент из девятой главы этой повести, который вполне, с самыми незначительными поправками, может быть отнесен и к герою Достоевского:

«Леон на десятом году от рождения мог уже часа по два играть воображением и строить замки на воздухе. Опасности и героическая дружба были любимою его мечтою. Достойно примечания то, что он в опасностях всегда воображал себя избавителем, а не избавленным: знак гордого, славолюбивого сердца! <...> Такое донкишотство воображения заранее определяло нравственный характер Леоновой жизни. Вы, без сомнения, не мечтали так в своем детстве, спокойные флегма-

2 Имя Карамзина упомянуто в «Идиоте» лишь однажды: Лебедев утверждает, что имя Мышкина фигурирует в «Истории государства Российского» [Достоевский 1972-1990: VIII, 8]; см. об этом подробнее: [Федоров 2004: 365-366]. Вопрос об восприятии Достоевским его наследия обсуждается давно; из работ недавнего времени см., в т.ч.: [Туниманов 1980; Архипова 1983; Жилякова 1992; Жилякова 1974; Белов 2001: 142-158; Вертлиб 1997; Глухов 1999; Виролайнен 2003; Кацис 2017; Криницын 2017]; обобщающий опыт изучения рецепции Карамзина в XIX в.: [Сапченко 2003]. 
тики, которые не живете, а дремлете в свете и плачете только от одной зевоты! И вы, благоразумные эгоисты, которые не привязываетесь к людям, а только с осторожностию за них держитесь, пока связь для вас полезна <...>.

Сверх того, он любил грустить, не зная о чем. Бедный!.. Ранняя склонность к меланхолии не есть ли предчувствие житейских горестей?.. Голубые глаза Леоновы сияли сквозь какой-то флер, прозрачную завесу чувствительности. Печальное сиротство еще усилило это природное расположение ко грусти. Ax! Самый лучший родитель никогда не может заменить матери, нежнейшего существа на земном шаре! Одна женская любовь, всегда внимательная и ласковая, удовлетворяет сердцу во всех отношениях!..» [Карамзин 1802-1803: 14, 122-124].

Нетрудно заметить, что Лев Мышкин Достоевского и Леон (кстати, именно так называли Мышкина швейцарские дети) Карамзина соотносимы друг с другом: общими являются меланхолия, мечтательность (при том что мечтательность князя была иной, не героической), «донкихотство», сиротство, детали портрета (в обоих случаях голубые глаза) и даже душевная болезнь (первой публикации девятой и последующих глав Карамзин предпослал небольшую заметку об «авторе» «Рыцаря нашего времени»; здесь говорилось: «Сей роман вообще основан на воспоминаниях молодости, которыми Автор занимался во время душевной и телесной болезни: так по крайней мере он нам сказывал <...> [Карамзин 1802-1803: 14, 121]).

Но зафиксировав это сходство, вновь зададим вопрос. Насколько обязательным является восприятие Мышкина на фоне Леона? Ответ напрашивается сам собой: ни на сколько, потому что в тексте Достоевского нет ничего, что в самом деле обязывало бы читателя помнить или вспоминать «Рыцаря нашего времени», т.е. нет прямых указаний на повесть Карамзина и ничего, что не могло бы быть понято без обращения к этому источнику. Перед нами необязательно-мерцающий подтекст/контекст, вполне допускающий активизацию в смысловом пространстве «Идиота» и с той же легкостью остающийся за его пределами.

Такого рода литературные контексты необязательны и в том смысле, что даже если они каким-то образом «проясняются» в результате усилий исследователей до уровня минимальной доказательности, они ничего - по крайней мере, на первый взгляд - не решают, ограничиваясь сферой разного рода литературных игр на периферии, не затрагивая, как будто, смысловое ядро, причем в каждом конкретном случае воз- 
можны разные интерпретации этих литературных игр, и выбор между этими интерпретациями далеко не всегда очевиден (при том что иногда возникает соблазн именно эту периферию выдвинуть в центр). Так происходит всегда, когда мы сопоставляем фрагменты текстов, сходные по смыслу, даже по лексическому составу, по синтаксису, не имея при этом никаких гарантий, что наше сопоставление адекватно авторскому замыслу, кругозору и т.д.

Думаю, что есть другой путь обсуждения подобных тем: перевести его на уровень описания литературного пространства, с которым непосредственно взаимодействует интересующий нас автор / текст, и найти в этом пространстве место для интересующего нас необязательного контекста - или констатировать, что места там для него нет.

Поэтому в данной заметке мы, отвлекаясь от множества существенных деталей, которые целесообразно обсуждать отдельно, не ищем «цитаты» Достоевского из Карамзина, а пытаемся кратко описать (в сущности, только обозначить) то литературное пространство, с которым взаимодействуют тексты Достоевского и, в частности, роман «Идиот». В первом и грубом приближении это «сентиментальность» («сентиментализм») и романтизм (преимущественно с уклоном в готику), воспринятые через посредство Пушкина, Гоголя и раннего «натурализма». Данная матрица, во-первых, отмечена, как минимум двойной динамикой (пушкинское и гоголевское начала могут соотноситься друг с другом, взаимодействовать, а могут противопоставляться; одновременно «натурализм» может резко отделять себя от всего предшествующего, а может, обычно неявным образом, взаимодействовать и с пушкинско-гоголевской парадигмой, и с сентиментально-романтической, причем именно в тех точках сверконцептуальности, которые аккумулируют различные аспекты темы падшего мира [«реальной жизни» в ее собственных формах], в пределе устремленной к гностическому контексту). Во-вторых, она может взаимодействовать или даже, попросту говоря, наполняться широким кругом идей и идеологий - в диапазоне от «розового социализма» до церковной ортодоксии почти в любых проекциях и сочетаниях; при этом неизбежно активизируются некоторые жанровые парадигмы, понимаемые опять-таки динамически - в диапазоне от религиозной мистерии барочного типа до бульварного романа.

Но мы условились сузить тему: здесь нас интересует только один из сегментов этой матрицы, именно первый из перечисленных, т.е. «сентиментализм», и конкретно первый альманах Карамзина, специфика 
которого заключается в том, что это был альманах одного автора и по этой причине может рассматриваться как единый текст особого типа3 Посмотрим же, чем мы располагаем.

Во-первых, конечно, именем Аглая, которым Достоевский наделяет одну из героинь своего романа и которое послужило Карамзину заглавием его альманаха. Мы не можем здесь подробно останавливаться на литературной истории этого имени, а потому отметим лишь, что интерес русских литераторов к нему усилил, если не сформировал, именно альманах Карамзина. Во всяком случае, журналы «карамзинского направления» или близкие к нему дают некоторый материал по теме;

3 Лишь три произведения из числа помещенных в нем не принадлежат Карамзину; однако он имитировал разнообразие, используя различные подписи под собственными текстами. Это, впрочем, относится ко второй книжке альманаха, так как в первой подписаны лишь те два текста, которые поступили от И.И. Дмитриева и М.М. Хераскова. «Послание к Д***» подписано «А.Б.В.», стихотворения «Любезной, в день ее рождения» и «Странность любви, или Бессонница», помещенные рядом, - криптонимом «О.О.», «Притча, Скворец, попугай и сорока» - «М.-в», а повесть «Сиерра-Морена» снабжена подзаголовком «Элегический отрывок из бумаг N». И лишь «М.-в» указывает на реальное лицо - М.М. Хераскова, прочие подписи мистифицирующие. Судя по всему, некоторые межтекстовые переклички, по замыслу Карамзина, должны были восприниматься читателями как переклички между текстами различных авторов, а цитаты - как цитаты из чужого текста (так, в конце неподписанного «письма» «Филалет к Мелодору» цитируется подписанное только что указанным криптонимом «Послание к $\left.Д^{* * *}\right)$. Напомним в этой связи, что по-разному подписывал Карамзин свои сочинения и в дальнейшем, ср.: «В Вестнике Европы <...> поражает нас обилие подписей, придуманных Карамзиным для себя. Сам он объяснял отсутствие своей фамилии таким образом: «Удовольствие читателей казалось мне важнее авторского хвастовства, и для того я не подписывал своего имени под сочинениями» <...>. Но не трудно, кажется, разгадать настоящую причину этого. Он наполнял журнал большею частию своими произведениями; между тем на него стали ополчаться многие критики; их приговоры раздражали его самолюбие; но отвечать на них он не хотел, полемики не любил, и не видел в ней пользы; желая сохранить свое имя от журнального поминательства, он стал подписывать свои сочинения разными затейливыми подписями» [Пономарев 1883: 51-52]. Этих последних исследователь насчитал двадцать пять. Объяснение же, данное им, разумно, но недостаточно: Карамзин не просто выпускал журналы и альманахи, он стремился влиять на литературный процесс, формируя новое направление, и конструировал его образ, обозначая существование союзников. Именно поэтому в «Аглае» заметно некоторое движение к форме альманаха многих авторов, каким стали «Аониды» (об альманахе одного автора см.: [Skrunda 1974: 98-106]). Однако мистификация, к которой прибегнул Карамзин, была им же дезавуирована, правда лишь отчасти и лишь в отношении первой части альманаха. В заметке «От сочинителя», которой завершалась первая книжка «Аглаи», говорилось: «Наконец - вот первая книжка! В ней одни Руския сочинения; переводов нет. На сей раз приятели мои сообщили мне только две пиесы: басню чиж и разлуку» [Аглая 1796: 1, 144]. Итак, читателям предлагалось уяснить, что все напечатанные здесь пьесы, кроме этих двух, принадлежат издателю. В конце посвящения второй книжки Карамзин счел нужным отметить: «И в сей книжке нет ничего, кроме Рус $<$ с $>$ ких сочинений» [Аглая 1796: 2, 6]. О приятелях автора, нерешительность которых, видимо, несколько смутила издателя, когда он собирал первую книжку своего альманаха, не сказано ни слова: на этот раз читателю предлагается самому догадываться о том, кто был автором новейших «Рус $<\mathrm{c}>$ ких сочинений» - издатель или расписавшиеся наконец его приятели. 
см., напр.: [Львов 1795; Магницкая 1797; Поляков 1799]; см. также напечатанную без подписи и менее снисходительную к Аглае повесть: [Путешественницы 1795]. Позднее имя Аглая (как представляется, никак не менее, а скорее всего существенно более важное для русской литературы, чем другое «карамзинское» женское имя, Лиза) встречается у И.М. Борна, И.И. Дмитриева, П.И. Шаликова, В.А. Жуковского, Д.В. Давыдова, К.Н. Батюшкова, А.А. Шаховского (в литературно-полемическом контексте), А.С. Пушкина (в скабрезно-игровом контексте), А.С. Грибоедова, К.Ф. Рылеева, В.К. Кюхельбекера, А.Ф. Вельтмана, Е.А. Баратынского, А.И. Полежаева, В.Г. Бенедиктова, А.Н. Майкова, М.Н.Загоскина, Г.П. Данилевского, В.А. Вонлярлярского, Б.М. Маркевича,А.Я.Марченко,А.Н.Островского,В.В.Крестовского,А.Ф.Писемского, М.Е. Салтыкова-Щедрина, И.Н. Потапенко, А.П. Чехова, А.В. Амфитеатрова, Ф.К. Сологуба, В.Ф. Ходасевича, И.А. Бунина, 3.Н. Гиппиус, Андрея Белого и др. (разумеется, отнюдь не всегда сохраняя непосредственную связь с текстами Карамзина).

Название альманаха Карамзина восходило к его же «Московскому журналу» (продолжением которого, как это было заявлено самим издателем, и была «Аглая»), ср. в наброске «Невинность»:

«Веселие сияет в очах ея. Она улыбается подобно утру весеннему. На высоком челе ея изображается душевный мир и спокойствие. Неувядаемыя розы и лилии цветут на ее ланитах. Стан ея подобен прямому стеблю нежного нарцисса. Резвые зефиры, виясь вокруг ея, развевают на ней легкую, белую одежду, и распущенными власами ея играют, но едва дерзают они прикасаться к девственным грудям ея, подобным чистейшему снегу двухолмистой горы в Гельвеции <...>, к которому ничто смертное не прикасалося. Увенчанная цветами Граций, шествует она бодро по земле благословенной; бури и мраки от нее удаляются; ядовитыя змии не смеют ужалить ноги ея; колючия травы смягчаются под ея стопами; Небесная благость изливается перед нею в лучах солнечных.

Когда смертные повиновались гласу благодетельной Природы, и жили в любви, тишине и мире: тогда Невинность на земле обитала, гуляла по лугам с пастушками, играла и пела с ними в хороводах. Но когда человек, в гибельный час заблуждения, восхотел быть мудрее Природы: тогда Невинность возвратилась на небеса, в свое отечество. С того времени, она уже редко посещает землю, и редко бывает видима оку смертного; но я видел ее - в образе любезной Аглаи» [Карамзин 1791: 65].

Тема Аглаи связывалась Карамзиным с темами времени, смерти, вечности: 
«Братия! я слышал пение райской птички, и не чувствовал тысячи лет!» - Тут хочет он изъяснить сладость сего пения; но язык его тупеет, взор его меркнет - он падает, и святая душа вылетает из тленнаго тела. На камне, покрывающем могилу его, вырезаны сии слова: он слышал пение райской птички, и не чувствовал тысячи лет <...>.

Любезная Аглая! я также не чувствую времени, когда внимаю твоему пению! [Карамзин 1791а: 200-201].

Ср. еще обращения автора к Аглае в «Лиодоре»: [Карамзин 1792: 307, 308, 309, 316]. См. также неподписанный и, видимо, не принадлежащий Карамзину переводной фрагмент из Гердера, значимого, конечно, не только для Карамзина, но и для других русских авторов, в том числе для Достоевского: «Множество иных богинь и нимф старались многоразличными образами украшать землю и радовались, любуясь прекрасным своим делом. / Но как сии цветки по большей части уже отцвели, а с ними отцвела и слава их и радость богинь; тогда Венера сказала своим Грациям: «Что вы медлите, сестры приятности? Сотките и вы из своих прелестей какой-нибудь смертный, видимый цветок!». Они сошли на землю. Аглая, Грация невинности, образовала лилию; Талия и Евфрозина вместе соткали цветок радости и любви, девственную розу» [Московский журнал 1791: 350-351).

В романе Достоевского Аглае, Талии и Евфросине, как известно, соответствуют сестры Епанчины: «В эти последние годы подросли и созрели все три генеральские дочери - Александра, Аделаида и Аглая. Правда, все три были только Епанчины, но по матери роду княжеского, <...> все три были замечательно хороши собой, не исключая и старшей, Александры, которой уже минуло двадцать пять лет. Средней было двадцать три года, а младшей, Аглае, только что исполнилось двадцать. Эта младшая была даже совсем красавица и начинала в свете обращать на себя большое внимание. Но и это было еще не всё: все три отличались образованием, умом и талантами. Известно было, что они замечательно любили друг друга и одна другую поддерживали. Упоминалось даже о каких-то будто бы пожертвованиях двух старших в пользу общего домашнего идола - младшей. В обществе они <...> были <... скромны. Никто не мог их упрекнуть в высокомерии и заносчивости, а между тем знали, что они горды и цену себе понимают. Старшая была музыкантша, средняя была замечательный живописец; но об этом почти никто не знал многие годы, и обнаружилось это только в самое последнее время, да и то нечаянно. Одним словом, про них говорилось чрезвычайно много похвального» [Достоевский 1972-1990: VIII, 15-16]. 
Как и полагается харитам, три сестры молоды, красивы, умны, образованы, погружены в стихию искусства (музыки и живописи), образуют нерасторжимое единство («они замечательно любили друг друга и одна другую поддерживали»). Но тут же рассказ о трех сестрах переключается в иронически-пародийный план, причем рядом с сестрами появляется их мать, наделенная еще одним «карамзинским» именем, отсылающем к самой знаменитой его повести: «Все три девицы Епанчины были барышни здоровые, цветущие, рослые, с удивительными плечами, с мощною грудью, с сильными, почти как у мужчин, руками, и, конечно вследствие своей силы и здоровья, любили иногда хорошо покушать, чего вовсе и не желали скрывать. Маменька их, генеральша Лизавета Прокофьевна, иногда косилась на откровенность их аппетита, но так как иные мнения ее <..> давно уже потеряли первоначальный $<\ldots>$ авторитет между ними, $<\ldots .>$ то и генеральша $<. .>$ нашла удобнее не спорить и уступать. Правда, характер весьма часто не <...> подчинялся решениям благоразумия; Лизавета Прокофьевна становилась с каждым годом всё капризнее и нетерпеливее, <...> но так как под рукой <...> оставался весьма покорный <...> муж, то излишнее и накопившееся изливалось обыкновенно на его голову, а затем гармония в семействе восстановлялась опять <...> [Достоевский 1972-1990: VIII, 32].

Итак, духовное оборачивается материальным, «небесное» - телесным, красота - физической силой, явным образом выходящей за пределы идеальной женственности и ее комически гипертрофирующей («мощная грудь» [ср. «девственные груди» в одном из приведенных выше фрагментов] и проч.), душевная близость - солидарностью в отстаивании права на реализацию гастрономических потребностей.

Во-вторых, рассказанная Мышкиным история о Мари и детях, своего рода чувствительная повесть о жестокости и сострадании, как неоднократно отмечалась, соотносится с соответствующей жанровой моделью, оформленной на русской почве Карамзиным, при том что Достоевский доводит до предела звучание основных мотивов такой повести - одиночества и беззащитности, сострадания (иногда понимаемого и как исключение из общего правила и как нравственный урок), физических и нравственных страданий, смерти / обреченности смерти в юном возрасте. Ср., например, как у Карамзина и Достоевского этот последний мотив сочетается с мотивами радости встречи (по-разному проявляющейся) и последней встречи, последнего рукопожатия, заходящего / исчезающего солнца, закрытых глаз / томного взгляда. Достоевский: «Она уж становилась очень больна и <...> сидела с закрытыми глазами <...> 
и дремала, тяжело дыша; лицо ее похудело, как у скелета, и пот проступал на лбу и на висках. <...> Я приходил на минуту, <...> Мари <...> вздрагивала, открывала глаза и бросалась целовать мне руки. <...> Мари опять оставалась одна, по-прежнему без движения, закрыв глаза <...>; она, может быть, о чем-нибудь грезила. <...> Накануне ее смерти, пред закатом солнца, я к ней заходил; кажется, она меня узнала, и я в последний раз пожал ее руку; как иссохла у ней рука!» [Достоевский 1972-1990: VIII, 62].

Карамзин: «Долговременная болезнь напечатлела знаки изнеможения на бледном лице его; в тусклых взорах изображалось телесное и душевное расслабление; огонь жизни простыл в его сердце, томном и мрачном. Едва мог он обрадоваться моему приезду, едва мог пожать руку мою; едва слабая, невольная улыбка блеснула на лице его, подобно осеннему солнцу, которое в лучезарном сиянии на минуту является и в облаках исчезает» [Аглая 1796: 1, 14-15].

Общим оказывается и мотив цветка / цветов на гробе: «<... они убрали ей весь гроб цветами. <...> C тех пор могилка Мари постоянно почиталась детьми: они убирают ее каждый год цветами, обсадили кругом розами»; ср. название очерка Карамзина, который мы только что цитировали: «Цветок на гроб Моего Агатона».

В той же первой книжке «Аглаи», где был напечатан этот очерк, помещена повесть «Остров Борнгольм», в которой впервые были намечен столь важный для Достоевского мотивный комплекс жалость, ужас, существование на грани жизни и смерти, обреченность, познание сокровенного зла в сочетании с наивностью того, кто впервые соприкасается с ним,. Во вторую книжку вошла повесть «Сиерра-Морена», содержащая описание самоубийства из ревности, выдержанного в стилистике «черной повести», которая ко времени Достоевского фактически сомкнулась с бульварным романом, ценившим эффекты, первыми читателями «Аглаи», воспринимавшиеся как литературная новация (напр.: «<..> вдруг явился незнакомец <..>, в черной одежде, с бледным лицом, с мрачным видом; кинжал блистал в руке его» [Аглая 1796: 2, 13]; ср.: «Лицо Рогожина было бледно <...>; глаза смотрели на князя пристально, с сильным блеском» [Достоевский 1972-1990: VIII, 502]; «Глаза Рогожина засверкали <...>. Правая рука его поднялась, и что-то блеснуло в ней» [Достоевский 1972-1990: VIII, 193].

B-третьих, роман Достоевского связан с альманахом Карамзина мотивами путешествия, русского путешественника за границей (напомним, что в «Аглае» продолжается печатание «Писем русского путешественника», начатое в «Московском журнале»). Князь Мышкин, 
впрочем, возвращается из Швейцарии (где, напомним, задумывался и писался роман «Идиот»), а «швейцарский» раздел «Писем русского путешественника» в «Аглаю» не попал, однако в ней содержатся комплиментарная «Надгробная надпись Боннету» [Аглая 1796: 1, 22], упоминание о нем в «Цветке на гроб моему Агатону» [Аглая 1796: 1, 9] и обширный пересказ разговора с ним в статье «Нечто о науках, искусствах и просвещении» [Аглая 1796: 1, 45-46], к которой нам еще предстоит вернуться (связь же тем Щвейцарии [«Гельветии»] и Аглаи, как видно из протицированного выше отрывка «Невинность», была зафиксирована Карамзиным еще в «Московском журнале») 4 .

Бонне, швейцарский философ и «натуралист», был также психологом и неврологом и, в частности, занимался галлюцинациями; князь Мышкин лечится в Швейцарии от «какой-то странной нервной болезни, вроде падучей или виттовой пляски» [Достоевский 1972-1990: VIII, 6], сопровождающейся «видениями». В тридцатитомном академическом собрании Достоевского имя Шарля Бонне не фигурирует, что, конечно, не означает, что оно было Достоевскому неизвестно, тем более что с именем Бонне теснейшим образом связана имевшая существенное значение для европейской культуры XIX в.тема палингенезии, которая обычно ассоциируется с Шопенгауром и о которой писали Гете, Гердер, Жан-Поль, Эккартсгаузен, и, конечно, именно Шарль Бонне, книгу которого «Палингенезия» упоминает (едва ли не как главное его сочинение) Карамзин в «Письмах русского путешественника», рассказывая о своем знакомстве с Бонне, который советовал ему переводить на русский язык именно эту свою книгу (не обсуждаем здесь сложный вопрос о некоторых скептических аспектах в целом почти апологетического отношения Карамзина к Бонне; см. об этом, напр., в недавней статье Н.К. Гаврюшина [Гаврюшин 2016: 134-135]). Отношение Достоевского к различным сочинениям, в которых обсуждается палингенезия, насколько нам известно, только начинает изучаться, хотя отдельные рассуждения, имеющие явно предварительный характер, уже появляются в соответствующей литературе (см., напр.: [Исупов 2001: 8]).

B-четвертых, все эти мотивы (путешествие, Швейцария, исследование сложных ментальных явлений) сочетаются с общей для Карамзина и Достоевского темой Руссо / «руссоизма», которая в обоих случаях интерпретируется двусмысленно и в обоих случаях антируссоизм резко выдвигается на первый план, при том что у Достоевского эта тенденция

4 О «швейцарской» теме в русской литературе, в т.ч. у Карамзина и Достоевского см., в частности: [Данилевский 1984; Меднис 2004; Степанян 2007]. 
выражена острее и ярче, а Карамзин, полемизируя с Руссо, продолжал оставаться в определенной зависимости от него. Впрочем, и Достоевский испытывал определенное тяготение к Руссо, ср.: «Достоевского неудержимо влекло к Руссо, но он сопротивлялся этому влечению и спорил всю жизнь с Руссо <...>. <...> Достоевский противопоставляет демократизм народности и видит в Руссо - проповеднике демократических идей - защитника антинародной буржуазности. Руссоизм становится для него «европейской» идеей в отличие от «русской»- христианства» [Лотман 1969: 603-604].

По-своему симптоматично, что заявив это, Ю.М. Лотман тут же проводит параллель между Достоевским и Карамзиным: «С этой позиции, как когда-то у Карамзина, «искренность» становится синонимом себялюбия, т. е. лжи, а «исповедь», обнажающий душу монолог, придается отрицательным героям <...>. Наслаждение исповедью равнозначно наслаждению самосозерцанием <...> [Лотман 1969: 604].

При этом Лотман готов рассматривать «игру в рассказы о дурных поступках на празднике у Настасьи Филипповны» как «явную пародию на сам принцип исповеди» [Лотман 1969: 604, примеч. 152]). Однако Лотман, убежденный в том, что эволюция отношения Карамзина к Руссо была сложной и драматической, имеет в виду Карамзина периода «Моей исповеди» (1802) и «Рыцаря нашего времени» (1803), полагая, что во время сочинения статей «Нечто о науках, искусствах и просвещении» и «Что нужно автору?» (обе 1793), напечатанных в первой книжке «Аглаи», отношение Карамзина к Руссо было существенно иным, поскольку характер этой эволюции обуславливался ходом европейских дел, т.е. в первую очередь французской революцией и ее последствиями, ср.: «Эта статья <«Нечто о науках...»> направлена против тезиса Руссо о вреде наук. Почему же Карамзин решил именно весной 1793 г. развернуть эту полемику? Причину он объяснил сам. Он опасался, что тактика революции - ее кровавые акции - будет использована для осуждения неизбежного и спасительного, по мнению Карамзина, движения народов по пути прогресса. В этих условиях он предвидел возможность использования аргументов Руссо для критики любого прогресса, для утверждения, что просвещение вредно, ибо неизбежно приводит к революции» [Лотман 1992-1993: 2, 93] .

5 Ср.: «Уже в «Аглае», полемизируя с Руссо, Карамзин в статье «Нечто о науках, искусствах и просвещении» на самом деле направил свои стрелы против тех, кто использовал страх правительства перед французской революцией для того, чтобы наложить узду на просвещение» [Лотман 1987: 261]. 
И далее в подтверждение своей версии Лотман цитирует «Нечто о науках <...»: « Карамзин писал: «Но Жан-Жака нет уже на свете: на что беспокоить прах его?» - Творца нет на свете, но творение существует; невежды читают его - самые те, которые ничего более не читают - и под эгидою славного Женевского Гражданина злословят просвещение» [Лотман 1992-1993, 2, 93].

Итак, Карамзин полемизирует с Руссо, чтобы аргументы последнего не могли быть использованы врагами просвещения; одновременно ему нужно отмежеваться от «якобинского» фона «руссоизма»: «Карамзин пытался отгородиться и от «якобинского» духа Руссо, и от реакции, прославляя быстрое, но эволюционное движение к идеалам, провозглашенным философами XVIII столетия. Статья оптимистична по своему духу и резко выделяется на фоне всего того, что писалось в эти дни в России о Франции, ее философах и политической жизни. Однако увидеть свет ей было суждено только в 1794 г., когда настроения Карамзина резко переменились. Якобинская диктатура и революционный террор потрясли его» [Лотман 1969: 583].

В статьях Лотмана, которые мы здесь цитируем, отнюдь не все представляется сформулированным убедительно. Например, не очень понятно, каким именно образом «“якобинский” дух Руссо» сочетался с его же отрицанием прогресса, взятым на вооружение «невеждами». Но сейчас для нас важнее другое: если в 1794 г. «настроения Карамзина резко переменились», непонятно, зачем он печатает свою статью, которая более не отражает его «настроений». Очевидно, что каковы бы ни были эти «настроения», их перемена была не настолько резкой, чтобы Карамзин захотел предать статью (или статьи) свою забвению; не говорим уже о том, что уверенно датировать завершение работы Карамзина по составлению первой книжки «Аглаи» мы сейчас не можем 6 . Наоборот, если он печатает старую статью в новых условиях, он считает ее акту-

6 Ю.М. Лотман считал, что «<...> вся первая часть альманаха была подготовлена весной 1793 г.», опираясь на скупые хронологические указания, которые содержатся в самой первой книжке «Аглаи» [Лотман 1957: 138, примеч. 41]). Но, во-первых, даже ограничиваясь ими, придется сдвинуть датировку на начало июня (третьим числом этого месяца датировано «Приношение Грациям» [Аглая 1796: 1, 5]; во-вторых, это будет именно нижняя дата (таким путем устанавливается лишь время, раньше которого работа над книгой не могла быть завершена); в-третьих, из писем Карамзина к И.И. Дмитриеву следует, что басню И.И. Дмитриева «Чиж» он получил 1 или 2 июня, что вновь, пусть и незначительно, выходит нас за пределы «весны»; и что 4 мая, обсуждая планы своего отъезда в деревню, который состоится через месяц, Карамзин сообщает, что надеется на «сельскую природу». которая должна «успокоить» его настолько, чтобы он смог «написать нечто и для Аглаu», работу над которой почти забросил («которою теперь мало занимаюсь») [Карамзин 1866: 35-36]; в деревню он отправился только 22 июня [Карамзин 1866: 38]. 
альной. Его полемика с Руссо не теряет своего значения в новом политическом контексте, а приобретает еще большее, как и основной вопрос расхождения с ним - вопрос о прогрессе. Именно этот вопрос выдвигается на первый план во второй книжке «Аглаи», в письмах Мелодора и Филалета, посвященных обсуждению трагических итогов XVIII столетия и прямо перекликающихся с рядом произведений, напечатанных в первой части альманаха, в т.ч. произведениями, полностью или частично посвященными Бонне, о котором мы уже упоминали выше и который мыслится Карамзиным как мыслитель, которого можно противопоставить Руссо, что и было сделано в статье «Нечто о науках...». В этой статье Карамзин говорил об истинном просвещении, которое считал «палладиумом благонравия», полагая, что нравственное воспитание неотделимо от любви к наукам, и связывал его (вряд ли только из тактических целей) с просветительскими проектами Екатерины II [Аглая 1796: 1, 71]; во второй книжке с представлениями о необходимости просвещения для образования чувствительных душ («Просвещение всегда благотворно; просвещение ведет к добродетели <...> [Аглая 1796: 2, 90]) сочетается тема веры в благость Провидения, развернутая в письме Филалета, ср.: «Пусть мир разрушится <...> и улыбка моя, среди всеобщих ужасов, скажет небу: Ты благо и премудро <...>. Неужели, видя Бога в естественном мире, <... будем мы отрицать Его <...> в одном нравственном мире, который по существу своему должен быть <...> ближе <...> к сердцу великого Божества?» [Аглая 1796: 2, 81]. Идея нравственного просвещения, конечно, была связана с масонским контекстом духовной биографии Карамзина; здесь нам придется еще раз процитировать Ю.М. Лотмана, который в своей ранней работе, отдавая дань времени ее сочинения, с неодобрением писал о статье Карамзине «Нечто об искусствах <...»: «Карамзин <...> соскальзывает на такое понимание лозунга просвещения, которое свойственно было масонам <...>. Пропагандируемое знание понималось как самопознание, <...> как путь к овладению страстями, к альтруизму. Мораль объявлялась венцом науки» [Лотман 1957: 138-139].

Разумеется, Карамзин никуда не «соскальзывал», поскольку представления, о которых писал Лотман, были глубоко усвоены Карамзиным в самом начале его духовного пути, и он никогда от них не отказывался. Их масонская подоплека, повторим, очевидна (как и близость религиозных представлений, декларируемых в «Аглае», к идее «внутренней церкви»), и именно наличие этой подоплеки объясняет относительное единство мировоззрения Карамзина на всех этапах его эволюции. Дру- 
гое дело, что в соответствии с динамикой внешних событий (как европейских, так и внутрироссийских) это мировоззрение поворачивалось различными своими сторонами и при этом вовсе не предполагало участия в масонских «работах».

Теперь вернемся к тому опыту защиты просвещения, который Карамзин предпринял в статье «Нечто о науках...»: как известно, тема была продолжена в письмах Мелодора и Филалета, и с существенно большим драматизмом: «Свирепая война опустошает Европу <...> И не только миллионы погибают; не только города и села исчезают в пламени <...> - сего не довольно: я вижу еще другое, ужаснейшее зло для бедного человечества.

Мизософы <...> торжествуют. «Вот плоды вашего просвещения! говорят они, - вот плоды ваших наук, вашей мудрости! Где воспылал огнь раздора, мятежа и злобы? Где первая кровь обагрила землю? И за что?.. И откуда взялись сии пагубные идеи?.. Да погибнет же ваша философия!» - И бедный, лишенный отечества, и бедный, лишенный крова, и бедный, лишенный отца, или сына, или друга, повторяет: «Да погибнет!» И доброе сердце, раздираемое зрелищем лютых бедствий, в горести своей повторяет: «Да погибнет!» - А сии восклицания могут составить наконец общее мнение <...>!» [Аглая 1796: 2, 68-59].

С этим вполне сопоставима логика героя Достоевского: «Нехристианская вера, <...> католичество римское <...> хуже самого атеизма <...>. Атеизм только проповедует нуль, а католицизм идет дальше: он искаженного Христа проповедует, <...> противоположного! Он антихриста проповедует <...>! <...> Папа захватил землю, земной престол и взял меч; с тех пор всё так и идет, только к мечу прибавили ложь, пронырство, обман, фанатизм, суеверие, злодейство, играли самыми святыми, правдивыми, простодушными, пламенными чувствами народа, всё, всё променяли за деньги, за низкую земную власть. <...> Атеизм прежде всего с них самих начался: могли ли они веровать себе сами? Он укрепился из отвращения к ним; он порождение их лжи и бессилия духовного! Атеизм! У нас не веруют еще только сословия исключительные, $<.$. >; а там, в Европе, уже страшные массы самого народа начинают не веровать, - прежде от тьмы и от лжи, а теперь уже из фанатизма, из ненависти к церкви и ко христианству!» [Достоевский 1972-1990: VIII, 450-451].

Итак, Мелодор сожалеет об утрате веры в философию, Мышкин - об утрате веры христианской; оба подчеркивают, что каждая из этих утрат катастрофична в том смысле, что за ними стоит «общее мнение» «страш- 
ных масс <...> народа». Мелодор обсуждает торжество мизософов, «врагов наук», т.е. религиозных фанатиков; ему - и им - отвечает Филалет: «Что принадлежит до мизософов, <...> то они <...> никогда торжествовать не будут. Знаю, что распространение <...> ложных идей наделало много зла <...>, но разве просвещение тому виною? Разве науки не служат <...> средством к открытию истины и к рассеянию заблуждений $<. .>$ ? Разве не истина, разве ложь есть существо наук? - Разогнем книгу истории; за что не лилась кровь человеческая? Например, распри суеверия вооружали сына против отца, брата против брата; но какой безумец вздумает обвинять тем самую религию?» [Аглая 1796: 2, 88-89].

«Безумец» Достоевского так и поступает, обвиняя, впрочем, не «самую религию», не христианство как целое, а одно из его направлений в уклонении от истины и в порождении атеизма, подобно тому, как Филалет, признавая, что «ложные идеи наделали много зла», обвиняет не «философию» как таковую, а именно уклонения от «философии» «истинной» (ср.: [Аглая 1796: 2, 71].

Если Карамзин сделал первый шаг к противопоставлению ложного / внешнего просвещения внутреннему и при этом осмыслил второе в религиозно-метафизическом ключе, то Достоевский, опиравшийся как на Карамзина, так и на всю последующую русскую традицию обсуждения вопроса, решительно и «окончательно» связал ее с противопоставлением России и Европы. При этом он, и именно в романе «Идиот», радикально оформил лишь намеченную у Карамзина связь всей данной проблематики с особыми состояниями души. Напомним, что карамзинский Мелодор, обсуждающий печальные итоги века просвещения, говорит и о себе, о своем «растерзанном сердце», о «печальных сомнениях», «несносной грусти», «хаосе души» [Аглая 1796: 2, 74-76]. Достоевский связывает своего героя с Руссо темой «естественного человека» (с подключением буколической топики, ассоциированной со значимой для Карамзина и «карамзинизма» темы душевной невинности, ср.: «О, князь, как вы еще светло и невинно, даже, можно сказать, пастушески смотрите на жизнь!» [Достоевский 1972-1990: VIII, 257]), но этот новый «естественный человек» страдает нервным заболеванием и в результате близкого соприкосновения с реальным миром в конце концов полностью теряет связь с ним, погружаясь в душевную болезнь; и эту печальную историю сопровождают те же мотивы «грусти, душевного мрака, давления», «волнения, <...> сомнения <...>, <...> беспокойства», длящейся «тоски»; все они, и у Карамзина, и у Достоевского, сочетаются с мотивом одиночества (у Карамзина: «Хладный мир! я тебя оста- 
вил! - Безумные существа, человеками именуемые, я вас оставил! <...> [Аглая 1796: 2, 17]; в другом месте: «Где ты, любезный Филалет? В каком уединении скрываешься?» [Аглая 1796: 2, 63]; у Достоевского: «Он был в мучительном напряжении и беспокойстве и в то же самое время чувствовал необыкновенную потребность уединения» [Достоевский 1972-1990: VIII, 186]), и в обоих случаях вся парадигма связывается с возможным выходом за пределы видимого мира: «Мелодор! Нам не век жить в сем мире. Ударит час, и все переменится! C сею любовию к добродетели, которая была, есть и будет вечным характером души твоей, падем в могилу и закроемся тихою землею!..

Там, там, за синим океаном,

Вдали, в мерцании багряном, там венец бессмертия и радости ожидает земных тружеников!»

([Аглая 1796: 2, 94]; см. также: [Аглая 1796: 2, 25]).

Сp. у Достоевского: «Это было в Швейцарии, в первый год лечения $<\ldots>$. Тогда он еще был совсем как идиот <...>. Он раз зашел в горы, в ясный солнечный день <...>. Пред ним было блестящее небо, внизу озеро, кругом горизонт светлый и бесконечный, которому конца-края нет. Он долго смотрел и терзался. Ему вспомнилось теперь, как простирал он руки свои в эту светлую, бесконечную синеву и плакал» [Достоевский 1972-1990: VIII, 351].

Наконец, в-пятых, на пределе развертывания темы духовной катастрофы возникает и тема гибели человечества, конца истории, тема, «которой Достоевский был одержим», сознавая, что «и “мировая гармония” и “последний мрак” реальные возможности», между которыми «должен быть сделан выбор, и Достоевский верил, сомневался, и снова верил, что выбор будет сделан в единственном направлении, в котором видимость бытия, лишь как тень, следует за самим бытием бытия <...> , вновь и вновь возвращаясь к вопросу, «может ли еще быть спасена непрерывность человеческого развития» и «можно ли еще продолжать то дело, без успеха которого немыслимо было бы и само приближение к абсолютным путям и задачам, дело мысли и сознания», или «все должно быть начато с начала, чтобы, быть может, все снова завершилось тем же концом» [Штейнберг 1923: 140]. Но именно эти две «реальные возможности» были впервые намечены у Карамзина, размышлявшего об обозначившейся во французской революции тенденции к исчерпанию нравственных возможностей истории и обобщившего эти размышления в форме эпистолярной дискуссии с открытым финалом, где первое письмо сконцентрировало в себе «последний мрак», а второе - надежду 
на возможность «гармонии». Умонастроение, описанное Штейнбергом применительно к Достоевскому, конечно, уже знакомо Карамзину, и можно было бы без потери смысла заменить в приведенных нами заметках Штейнберга имя Достоевского на имя Карамзина, который точно так же «верил, сомневался, и снова верил», точно также обдумывал «вечное движение в одном кругу; вечное повторение» [Аглая 1796: 2, 85] и едва ли не впервые раскрыл его во всем его драматизме, тем самым открыв путь другим русским писателям, соприкасавшимся с вызовами «последних вопросов», в т.ч. Достоевскому.

Теперь попробуем собрать все сказанное в некоторое условное единство. Итак, именно Карамзин, и именно в «Аглае», выстроив исключительно сложную смысловую конструкцию, которая опирается одновременно на представление о дискретности каждого отдельного текста и на готовность к ее преодолению в рамках заданной конструкции «альманаха одного автора», дал первый вариант обобщения той совокупности дилемм, которые связывают противопоставление зла и истины в человеке, в истории европейской цивилизации (и в этом смысле «человечества») с темой спасения и в аспекте «непрерывности развития», и в аспекте ее соотнесенности с широко понимаемой сферой надысторического («абсолютные пути и задачи»). Данная проблематика у Карамзина и у Достоевского оказалась связана с «руссоизмом», с выбором между представлением о развитии как прогрессе и как регрессе, с проблемой «естественного человеке» как идеале, чье воплощение в реальности общественной жизни невозможно, а актуализация неизбежна и необходима, и в обоих случаях устремлено за пределы земного времени-пространства. На противоположном полюсе - на границе или уже в пределах «реальности» - мотивный комплекс «жестокость сострадание/жалость, ужас, познание сокровенного зла в сочетании с темой душевной «невинности» и «болезни»/«болезненности», физической и душевной, наконец путешествия, понимаемого, в частности, как обретение не только культурного, но и нравственного опыта; в сердцевине же «падшего мира» остается «опрокинутая» в кругозор Лебедева «матричная» формула о «милом прахе» и «радостном утре». В той мере, в какой каждое отдельное произведение Достоевского взаимодействует с данной парадигмой, его «карамзинизм» открывается разными смысловыми гранями (при том, что каждая из этих граней определен- 
ным образом соотносится и с другими сегментами «литературного пространства», в т.ч., разумеется, с «готическим романтизмом», обычно не без оснований возводимым все к той же повести «Остров Борнгольм», впервые напечатанной в «Аглае»).

\section{Список литературы}

1. <Карамзин Н.М.> Рыцарь нашего времени // Вестник Европы. 1802. № 13. С. 35-51; № 18. С. $111-125 ; 1803$. № 14. С. 121-142.

2. Аглая / 2-е изд. Кн. 1-2. М., 1796. 335 с.

3. Архипова А.В. Достоевский и Карамзин // Достоевский: Материалы и исследования. Т. 5. Л.: АН СССР, ИРЛИ, 1983. С. 101-112.

4. Белов С.В. Вокруг Достоевского: Статьи, находки и встречи за тридцать пять лет. СПб.: Изд-во СПбГУ, 2001. С. 142-158.

5. Вертлиб Е. Карамзин и Достоевский // Дон. 1997. № 1. С. 208-214.

6. Виролайнен М.Н. Фома Опискин и Иван Грозный // Pro memoria: памяти акад. Г.М. Фридлендера (1915-1995). СПб.: Наука, 2003. С. 136-144.

7. Гаврюшин Н.К. Метафизика и историософия в творчестве Н.М. Карамзина // Тетради по консерватизму. 2016. № 4. С. 131-144.

8. Глухов В.И. «Моя исповедь» Карамзина в творческом сознании Достоевского // Национальные традиции и европеизм в русской культуре. Вып. 1. Ульяновск: УлГУ, 1999. C. 50-62.

9. Два цветка соперники к Аглае [перевод с франц. М.Л. Магницкой] // Приятное и полезное препровождение времени. 1797. Ч. 15. С. 207-208.

10. Достоевский Ф.М. Полн. собр. соч.: В 30 т. Л.; СПб.: Наука, 1972-1990.

11. Жилякова Э.М. «Фрол Силин» Н.М. Карамзина и «Мужик Марей» Ф.М. Достоевского // От Карамзина до Чехова: Сб. ст. Томск: Изд-во Томского ун-та, 1992. С. 81-95.

12. Жилякова Э.М. Традиции сентиментализма в творчестве раннего Достоевского (1844-1849). Томск: Изд-во Томского ун-та, 1999. 274 с.

13. Исупов К.Г. Читатель и автор в текстах Достоевского // Достоевский: Материалы и исследования. Вып. 16. СПб.: ИРЛИ РАН, 2001. С. 3-23.

14. К Аглае [перевод с немецк. В. Полякова] // Иппокрена. 1799. Ч. 2. С. 76-78.

15. Карамзин Н.М. Лиодор // Московский журнал. 1792. Ч. 5. Кн. 3. С. 305-334.

16. Карамзин Н.М. Невинность // Московский журнал. 1791. Ч. 2. Кн. 1. С. 64-65.

17. Карамзин Н.М. Письма к И.И. Дмитриеву. СПб.: Издание II-го Отделения Императорской Академии наук,1866. 727 с.

18. Карамзин Н.М. Райская птичка // Московский журнал. 1791. Ч. 3. Кн. 2. С. 198-201.

19. Кацис Л.Ф. Карамзин, Белинский и Достоевский в наброске Мандельштама «Преступление и наказание в “Борисе Годунове” // Stephanos. 2017. № 2. С. 87-98.

20. Криницын А.Б. Повесть Н.М, Карамзина «Бедная Лиза» в творчестве Ф.М. Достоевского // Вестник Московского университета. Серия 9: Филология. 2017. № 1-2. С. 102-116. 
21. Летопись жизни и творчества Ф.М. Достоевского: В 3 т. СПб.: Гуманитарное агентство «Академический проект», 1999. Том 1: 544 с. Том 2: 592 с. Том 3: 615 с.

22. Лотман Ю.М. Избранные статьи: В 3 т. Т. І. Статьи по семиотике и типологии культуры. Таллин: Александра, 1992. 478 с. Т. ІІ. Статьи по истории русской литературы XVIII - первой половины XIX века. Таллин: Александра, 1992. 478 с. Т. III. Статьи по истории русской культуры. Теория и семиотика других искусств. Механизмы культуры. Мелкие заметки. Таллин: Александра, 1993. 495 с.

23. Лотман Ю.М. Руссо и русская культура XVIII - начала XIX века // Руссо, ЖанЖак. Трактаты. М.: Наука, 1969. С. 555-604.

24. Лотман Ю.М. Сотворение Карамзина. М.: Книга, 1987. 336 с.

25. Лотман Ю.М. Эволюция мировоззрения Карамзина (1789-1803) // Ученые записки Тартуского гос. ун-та. Вып. 51. Тарту: Изд-во Тартуского ун-та, 1957. С. 122-162.

26. Львов П.Ю. На смерть моей Аглаи // Приятное и полезное препровождение времени. 1795. Ч. 8. С. 119-130.

27. Меднис H.E. Швейцария в художественной системе Достоевского (к проблеме формирования в русской литературе швейцарского интерпретационного кода) // Toronto Slavic Quoterly. 2004. № 4 [Электронный ресурс]. - Режим доступа: http:// sites.utoronto.ca/tsq/11/mednis11.shtml

28. Московский журнал. 1791. Ч. 1. Кн. 1. С. 349-351.

29. Пономарев С.И. Материалы для библиографии литературы о Н.М. Карамзине: К столетию его литературной деятельности: (1783-1883) (Сборник Отделения русского языка и словесности Имп. Академии наук. Т. 32. № 8). СПб.: Тип. Имп. акад. наук, 1883. $156 \mathrm{c}$.

30. Путешественницы // Магазин для распространения общеполезных знаний и изобретений, с присовокуплением Модного Журнала, раскрашенных рисунков и музыкальных нот. 1795 . № 2. С. 108-125.

31. Сапченко Л.А. Н.М. Карамзин: судьба наследия (век ХІХ). М.; Ульяновск: УлГУ, 2003. 379 c.

32. Степанян К.А. Достоевский и Швейцария // Проблемы истории, филологии, культуры. 2007. № 18. С. 113-121.

33. Туниманов В.А. Отголоски девятого тома «Истории государства Российского» в творчестве Ф.М. Достоевского // Slavia. 1980. Вып. 4. С. 350-360.

34. Федоров Г.А. Московский мир Достоевского: Из истории русской художественной культуры ХХ века. М.: Языки славянской культуры, 2004. 464 с.

35. Штейнберг А.З. Система свободы Достоевского. Берлин: Скафы, 1923. 146 с.

36. Skrunda Wiktor. Na marginesach wielkiej literatury: Ewolucja rosyjskich almanachów literackich lat 1794-1852. Wrocław; Warszawa; Kraków; Gdańsk: Zakład Narodowy im. Ossolińskich, 1974. 195 p. 


\section{References}

1. < Karamzin N.M.> Rycar' nashego vremeni // Vestnik Evropy. 1802 [Knight of our time. Vestnik Evropy. (In Russ.)] 1802. № 13. Pp. 35-51; № 18. Pp. 111-125; 1803. № 14. Pp. 121-142.

2. Aglaya / 2-e izd. Kn. 1-2 [Aglaya, 2nd ed. Book 1-2 (In Russ.)]. Moscow, 1796. 335 p.

3. Arhipova A.V. Dostoevskij i Karamzin // Dostoevskij: Materialy i issledovaniya. T. 5 [Dostoevsky and Karamzin. Dostoevsky: Materials and Studies. Vol. 5 (In Russ.)]. Leningrad, AN SSSR, 1983. Pp. 101-112.

4. Belov S.V. Vokrug Dostoevskogo: Stat'i, nahodki i vstrechi za tridcat' pyat' let [Around Dostoevsky: Articles, Findings and Meetings for Thirty Five Years (In Russ.)]. St. Petersburg, Izd-vo SPbGU, 2001. Pp. 142-158.

5. Dostoevskij F.M. Poln. sobr. soch.: V 30 t. [Complete Works in 30 vls. (In Russ.)]. Leningrad - St. Petersburg, Nauka, 1972-1990.

6. Dva cvetka soperniki k Aglae [perevod s franc. M.L. Magnickoj] // Priyatnoe i poleznoe preprovozhdenie vremeni. 1797. Ch. 15 [Two Flowers Rivals to Aglaya [translated from French by M.L. Magnitskyj]. Pleasant and Useful Pastimes. 1979. P. 15 (In Russ).]. Pp. 207-208.

7. Fedorov G.A. Moskovskij mir Dostoevskogo: Iz istorii russkoj hudozhestvennoj kul'tury HKH veka [The Moscow world of Dostoevsky: From the History of Russian Artistic Culture of the Twentieth Century (In Russ.)]. Moscow, Yazyky slavyanskoj kultury, 2004. 464 p.

8. Gavryushin N.K. Metafizika i istoriosofiya v tvorchestve N.M. Karamzina // Tetradi po konservatizmu. 2016. № 4 [Metaphysics and Historiosophy in the Works of NM. Karamzin. Notes on conservatism (In Russ.)]. Pp. 131-144.

9. Gluhov V.I. «Moya ispoved'» Karamzina v tvorcheskom soznanii Dostoevskogo // Nacional'nye tradicii i evropeizm v russkoj kul'ture. Vyp. 1 [Karamzin's "My confession" in the Creative Consciousness of Dostoevsky. National Traditions and Europeanism in Russian Culture. Issue 1 (In Russ.)]. Ul'yanovsk, Izd-vo UlGU, 1999. Pp. 50-62.

10. Isupov K.G. Chitatel' i avtor v tekstah Dostoevskogo // Dostoevskij: Materialy i issledovaniya. <Vyp.> 16 [Reader and Author in Dostoevsky's Texts. Dostoevsky: Materials and Studies. Is. 16 (In Russ.)]. St. Petersburg, IRLI RAN, 2001. Pp. 3-23.

11. K Aglae [perevod s nemeck. V. Polyakova] // Ippokrena. 1799. Ch. 2 [To Aglaya [translation from German by V. Polyakov]. Hippocrene. 1799. Part 2 (In Russ.)]. Pp. 76-78.

12. Kacis L.F. Karamzin, Belinskij i Dostoevskij v nabroske Mandel'shtama «Prestuplenie i nakazanie v "Borise Godunove” // Stephanos [Karamzin, Belinsky and Dostoyevsky in Mandelshtam's Draft “Crime and Punishment in "Boris Godunov"”. Stephanos. 2017. \# 2 (In Russ.)]. Pp. 87-98.

13. Karamzin N.M. Liodor // Moskovskij zhurnal. 1792. Ch. 5. Kn. 3 [Lyodor. The Moscow Journal. 1792. Part 5. Book 3 (In Russ.)]. Pp. 305-334.

14. Karamzin N.M. Nevinnost' // Moskovskij zhurnal. 1791. Ch. 2. Kn. 1[Innocence. The Moscow Journal. 1791. Part 2. Book 1 (In Russ.)]. Pp. 64-65.

15. Karamzin N.M. Pis'ma k I.I. Dmitrievu [Letters to I.I. Dmitriev (In Russ.)]. St. Petersburg, Izdanie II-go otdelenija Imperatorskoj academii nauk, 1866.727 p. 
16. Karamzin N.M. Rajskaya ptichka // Moskovskij zhurnal. 1791. Ch. 3. Kn. 2 [Bird of Paradise. Moscow Journal. 1791. Part 3. Book 2 (In Russ.)]. Pp. 198-201.

17. Krinicyn A.B. Povest' N.M, Karamzina «Bednaya Liza» v tvorchestve F.M. Dostoevskogo // Vestnik Moskovskogo universiteta. Seriya 9: Filologiya. 2017. № 1-2 [N.M. Karamzin’s Story "Poor Liza" in the Works of F.M. Dostoevsky. Bulletin of Moscow University. Series 9: Philology. 2017. № 1-2.]. Pp. 102-116.

18. Letopis' zhizni i tvorchestva F.M. Dostoevskogo: V 3 t. [The Chronicle F.M. Dostoyevsky's of Life and Work: in 3 vls. (In Russ.)]. St. Petersburg, Akademicheskij proekt, 1999. Vol. 1: 544 p. Vol. 2: 592 p. Vol. 3: 615 p.

19. Lotman Y.M. Izbrannye stat'i: V 3 t. [Selected Articles: in 3 vls. Vol. I. Semiotics and Typology of Culture. $478 \mathrm{p}$. Vol. II. The History of Russian Literature of the XVIII $-1^{\text {st }}$ Half of the XIX Century. 478 p. Vol. III. The History of the Russian Culture. Theory and Semiotics of the Other Arts. Mechanism of Culture. Small Notes. 496 p. (In Russ.)]. Tallinn, Alexandra, 1992-1993.

20. Lotman Y.M. Sotvorenie Karamzina [Creation of Karamzin (In Russ.)]. Moscow, Kniga, $1987.336 \mathrm{p}$.

21. Lotman Y.M. Evolyuciya mirovozzreniya Karamzina (1789-1803) // Uchenye zapiski Tartuskogo gos. un-ta. Vyp. 51 [Evolution of Karamzin's World View (1789-1803). Bulletin of Tartu University (In Russ.)]. Tartu, Izd-vo Tartuskogo un-ta, 1957. Pp. 122-162.

22. Lotman Y.M. Russo i russkaya kul'tura XVIII - nachala XIX veka // Russo, Zhan-Zhak. Traktaty [Rousseau and the Russian Culture of the XVIIIth - early XIXth Centuries. Rousseau, JeanJacques. Treatises (In Russ.)]. Moscow, Nauka, 1969. Pp. 555-604.

23. L'vov P.Y. Na smert' moej Aglai // Priyatnoe i poleznoe preprovozhdenie vremeni. 1795. Ch. 8 [On the Death of My Aglaya. Pleasant and Useful Pastimes. 1794. P. 8 (In Russ.)]. Pp. 119-130.

24. Mednis N.E. SHvejcariya v hudozhestvennoj sisteme Dostoevskogo (k probleme formirovaniya v russkoj literature shvejcarskogo interpretacionnogo koda) // Toronto Slavic Quoterly [Switzerland in the Artistic System of Dostoevsky (to the Problem of the Creation of a Swiss Interpretation Code in Russian Literature) (In Russ.)]. 2004. № 4 [Electronic resource]. - Access code: http://sites.utoronto.ca/tsq/11/mednis11.shtml

25. Moskovskij zhurnal. 1791. Ch. 1. Kn. 1 [Moscow Journal. 1791. Part 1. Book 1 (In Russ.)]. Pp. 349-351.

26. Ponomarev S.I. Materialy dlya bibliografii literatury o N.M. Karamzine: K stoletiyu ego literaturnoj deyatel'nosti: (1783-1883). (Sbornik Otdeleniya russkogo yazyka i slovesnosti Imp. Akademii nauk. T. 32. № 8) [Materials for the Bibliography of Literature on NM. Karamzine: To the Centenary of His Literary Career: (1783-1883). (Collection of the Department of the Russian Language and Literature of the Imperial Academy of Sciences. Vol. 32. No. 8 (In Russ.)]. St. Petersburg, Typ. Imp. acad. nauk,1883. 156 p.

27. Puteshestvennicy // Magazin dlya rasprostraneniya obshchepoleznyh znanij i izobretenij, s prisovokupleniem Modnogo ZHurnala, raskrashennyh risunkov i muzykal'nyh not [Women Travelers. A Store for the Spread of General Knowledge and Inventions, with the Addition of the Fashion Magazine, Painted Drawings and Musical Notes (In Russ.)]. 1795. № 2. Pp. 108-125. 
28. Sapchenko L.A. N.M. Karamzin: sud'ba naslediya (vek XIX) [N.M. Karamzin: the Fate of the Heritage (19 ${ }^{\text {th }}$ century) (In Russ.)]. Moscow, Ul'yanovsk, Izd-vo UlGU, 2003. 379 p.

29. Shtejnberg A.Z. Sistema svobody Dostoevskogo [Dostoyevsky's System of Freedom (In Russ.)]. Berlin, Skafy, 1923. 146 p.

30. Stepanyan K.A. Dostoevskij i Shvejcariya // Problemy istorii, filologii, kul'tury [Dostoevsky and Switzerland. Problems of History, Philology, Culture (In Russ.) ]. 2007. № 18. Pp. 113-121.

31. Tunimanov V.A. Otgoloski devyatogo toma «Istorii gosudarstva Rossijskogo» v tvorchestve F.M. Dostoevskogo // [Echoes of the $9^{\text {th }}$ Volume of the "History of the Russian State" in the Works of F.M. Dostoevsky. Slavia. 1980. Is. 4 (In Russ.)]. Pp. 350-360.

32. Vertlib E. Karamzin i Dostoevskij // Don. 1997. № 1 [Karamzin and Dostoevsky. Don. 1997. \# 1 (In Russ.)]. Pp. 208-214.

33. Virolajnen M.N. Foma Opiskin i Ivan Groznyj // Pro memoria: pamyati akad. G.M. Fridlendera (1915-1995) [Foma Opiskin and Ivan the Terrible. Pro memoria: memory of acad. G.M. Friedlander (1915-1995) (In Russ.)]. St. Petersburg, Nauka, 2003. Pp. 136-144.

34. Zhilyakova E.M. «Frol Silin» N.M. Karamzina i «Muzhik Marej» F.M. Dostoevskogo // Ot Karamzina do CHekhova: Sb. st. ["Frol Silin" by N.M. Karamzin and "Muzhik Marey" by F.M. Dostoevsky // From Karamzin to Chekhov. Collected Articles (In Russ.)]. Tomsk, Izd-vo Tomskogo un-ta, 1992. Pp. 81-95.

35. Zhilyakova E.M. Tradicii sentimentalizma v tvorchestve rannego Dostoevskogo (1844-1849) [Traditions of Sentimentalism in the Works of Early Dostoevsky (1844-1849) (In Russ.)]. Tomsk, Izd-vo Tomskogo un-ta, 1999. 247 p. 